\title{
Corona Virus Transmission and Controls Challenge Mystery for Dentists (Systematic Review)
}

\author{
Rawaa Younus Al-Rawee ${ }^{1 *}$ and Mustafa Mohammed Saeed ${ }^{2}$ \\ ${ }^{1}$ Department of Oral and Maxillofacial Surgery, Al-Salam Teaching Hospital, Mosul, Iraq \\ ${ }^{2}$ Dental Health Specialist Centre, Ministry of Health, Al-Wahda City, Mosul, Nineveh, Iraq
}

${ }^{*}$ Corresponding author: Rawaa Younus Al-Rawee, BDS, MSc, OS, MOMS MFDSRCPS Glasgow Ph.D. MaxFacs, Department of Oral and Maxillofacial Surgery, Al-Sukar City, Mosul, Nineveh, Iraq; Tel: 009647726438648.

Received: June 24, 2020; Accepted: July 04, 2020; Published: July 07, 2020

\begin{abstract}
Objective: Authors aim here to high light important distinctive information with the guidelines which should be known and practiced in these challenged situations. These done by give brief overview on the epidemiology, symptoms and routes of transmission of this unique infection. As well, specific recommendations for dental practice are suggested for patient screening, infection control strategies and patient management protocol. Finally we high lighting the protection mode followed in my governorate to avoid the dissemination of the crisis.
\end{abstract}

Material and Method: Citation of more than 75 articles discuss corona virus dilemma which attacks widely different countries, we arranging and assess the information in brief method. Dentists with regardless to different specialty can be source of outbreak of such serious disease.

Conclusion: Protection of public in an intensive crisis such as Corona virus disaster are responsibilities of all with no exception starting from individuals themselves and ending with the Prime Minister. Its logical from the evidence based research that dealing with the crisis is challenge to all, moreover is imperative to improve current real strategies for anticipation and protection.

Highlight

COVID attacks are life threatening for patients similar to fire in wildfire.

Dentists Role in COVID Virus crisis outbreak is highly substantial.

Dentists are liable to handle their role in prevention and protection.

Dental care providers need to be aware for tackling any impending crisis challenge.

Keywords: COVID virus attack, Transmission, Precaution, Person protection, Dentists role

\section{Introduction}

In $10^{\text {th }}$ March 2020 , the whole world faces a globally dangerous random attack by specific, enveloped, nonsegmented, single-strand RNA viruses termed as Coronavirus [1,2]. The Challenge attack story started, in December 2019 when the World Health Organization) WHO( in China Wuhan state received information regarding some cases were detected of pneumonia of unknown aetiology [3] and extracting a novel coronavirus from lower respiratory tract sample of many cases. This novel beta coronavirus presently named 2019 novel coronavirus (2019-nCoV) [4].

Since February 26, COVID-19 is found in many countries (34), a total of 2,700 deaths an 80,239 laboratory-confirmed patients [5].

Evidence-based articles showed that family settings and hospitals were the main causes of the virus individual transmission [6-10]. This constitutes an emergency of public health in the global context as the WHO declared [11].
Cross infection in dentistry has particular attention for many infectious diseases as hepatitis or AIDS. Now a day in such exceptional situations where COVID virus gripped the countries leaving sadness with extraordinary mortality rate [12,13]. Cross infection considered high between dental practitioners and patients with different causes [14].

Great efforts are taken place to comprise the disease spread by different wide range institutions but despite these efforts, the outbreak is rising quickly because of the social gathering patterns of this infection. Covid19 has been considered as a zoonotic infection, similar to diverse infections of coronavirus, is thought to be originated in pangolins and bats, then, it was transmitted to human beings [15].

When the virus "Coronavirus (SARS-CoV-2)" is transmitted to persons' body is plentifully presented secretions of salivary and nasopharyngeal of patients. It is believed that the spread is respiratory contact/droplet in nature [15]. 
North Carolina department of health and human declares that "Dental providers have an important role in the overall effort to contain COVID-19, and those who work in local health departments and health clinics are essential to ensuring that care is available to high-risk members of our community" [16].

Dentists with regardless of a different speciality can be a source of an outbreak of such serious disease. For that, we aim here to high light important distinctive information with the guidelines which should be known and practised in these challenging situations. These were done by giving a short sketch on the routes of transmission, symptoms and epidemiology, of this exclusive infection. As well, some suggestions were given regard to patient management protocol, patient screening, dental practices and infection control strategies. Finally, in this article we high lighting the protection mode followed in my governorate to avoid the dissemination of the crisis.

\section{Materials and Method}

Assessment of 75 article discuss COVID Virus through network services. Authors analyzed articles in three axes; these are general information with guidelines that should known by dentist, role of dentists in preventing transmission, proved protections protocol published in articles. Excluding about 30 articles not specified on COVID Virus. Screening approved web page, publish documents, published systemic reviews, in press articles.

\section{Ethical Approval}

Compliance with ethical standards as its review, no ethical approval need.

\section{Epidemiologic Characteristics}

\section{Types}

Coronaviruses were called so because of their surface's spikes which looks like a crown (Figure 1). Its Firstly was determined in the middle of sixties -1960s. Four common human coronaviruses which can attack humans which are: HKU1 (beta coronavirus), OC43 (beta coronavirus), 229E (alpha coronavirus), and NL63 (alpha coronavirus). Other human types which occur newly are SARS-CoV-2 (COVID-19, or the novel coronavirus 2019) SARS-CoV (SARS or the
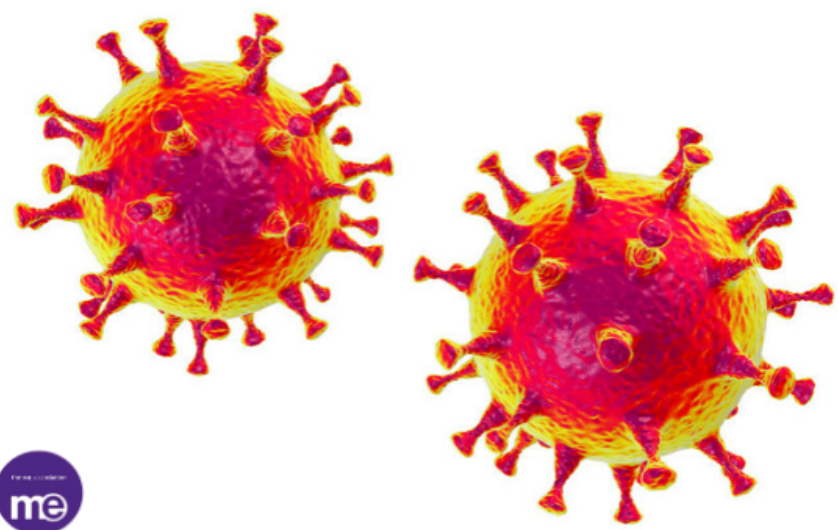

Figure 1: Crown-like spikes of Corona Virus (COVID 19). Cited from Charles Shepherd [70]. beta coronavirus that causes the severe acute respiratory syndrome, or) and the final disseminated dangerous type MERS-CoV (MERS or the beta coronavirus that causes Middle East Respiratory Syndrome, or) [17].

\section{Transmission Mode}

Genetic and epidemiological research confirmed that COVID dissemination is transmitted from human-to-human spread after the single animal-to-human transmission [18,19] Interpersonal contact transmission has been proved to be the main source for outbreak specifically with respiratory droplets [20]. Consequently, sneezing or coughing of the infected patient is capable distribute virus aerial ending potentially which transmit the virus to the close people and infect them with. Articles advocate that approximately 6 feet radius needed for protection [15].

Inanimate objects also can be considered as another important transmission route specifically if it's nearby to infected person respiratory droplets through sneeze or cough. Latest reports think that the virus can withstand for nine days on a hard surface like metal or plastic [15].

Studies approve that Virus has a great ability to connect to human angiotensin-converting enzyme 2 (ACE-2) positive cells that concentrated abundantly in salivary gland [21]. For that saliva also can play a role in transmission in the dental office setting [22].

Naso-Oropharyngeal droplets ordinarily associated with saliva. Distance dissemination for larger droplets could influence nearby subjects, and, vice versa, smaller droplets can infect the long-distance subjects $[8,23]$.

Various researches warned that asymptomatic persons can also be a source of the outbreak. This has been approved in tow studies done in China, Italy and Japan were viruses disseminated as like wildfire $51 \%, 44 \%$ and $0.06 \%$ of the laboratory-confirmed cases [24-26].

International mission reports of the World Health Organization stated in that majority of the cases $(75 \%)$ of newly infected patients will be developed to be the clinical disease, based on Chinese data [27].

Published case reports focus on pre-symptomatic transmission proportion estimated is around $48 \%$ and $62 \%$ [28] which expected to be based on a shorter serial interval of COVID-19 [4.0 to 4.6 days] rather than the mean incubation period (five days) recorded in symptomatic cases as secondary transmission detected [29].

Rothe C. stated in his article that till know its unproved that recovered patients can be a source of transmission of disease [8].

\section{Age, Gender and Existing Medical Condition Risk}

Generally speaking, all age group are susceptible for infection this estimated by the current observations in hospitals all over the worlds with priorities to medically compromised people above 60 years of age, males frequently considered at high risk and death [30-34].

In a study done by Wei-Jie Guan [35] describe that "the median age was 47.0 years (IQR, 35.0 to 58.0 ), and $41.9 \%$ were females. $0.9 \%$ 
of the patients were aged below 15 years. For clinical manifestation fever $(87.9 \%)$ and cough $(67.7 \%)$ were the most common symptoms, whereas diarrhoea $(3.7 \%)$ and vomiting $(5.0 \%)$ were rare. $25.2 \%$ of patients had at least one underlying disorder (i.e., hypertension, chronic obstructive pulmonary disease)".

Tobacco-users/smokers and those with hypertension are expected to be with high risk too, this can be attributed to the fact of ACE 2 expression in the tissues of the lungs maximize with age, hypertensive treatment, and users of tobacco,-. Thus, it's critical to state that tobacco-users are possibly a vulnerable group for COVID-19 [36-39].

Clinical observation also indicates that children experience mild clinical manifestations despite that they are likely to be infected as adults, [24,40]. World Health Organization highlighted that cases that are less than 19 years old constitute $2.4 \%$ of the overall infected patients in China [as of 20 February 2020]. A few portions of this group have a critical disease $(0.2 \%)$ or developed severe (2.5\%) [34]. On the whole, medically compromised older ages were associated with poorer prognosis [41-44].

Health care workers are also vulnerable to be infected as a study done by L. Meng analyzed 138 hospitalized infected cases who have the virus in Wuhan, in the early epidemic stage 40 (29\%) are health care workers $[10,41,43]$.

\section{Incubation Period}

This period of infection is able to last for $14 \mathrm{~d}$ although at start of attack of disease the incubation period expected to be 5 to $6 \mathrm{~d}$ on average. To date the fourteen days consider the regularly adopted period for quarantine and medical observation of (possible) exposed cases [45]. Moreover incubation period of patients as well asymptomatic patients are evidenced to be carriers in some articles to be another sources for outbreak $[8,18]$.

\section{Clinical Manifestations}

According to recent studies $[35,44]$ most of the of COVID-19 patients with considered as moderately mild cases while sever cases among all patients was $15 \%$ to $25 \%$. Fever, fatigue, dry cough, breath shortness, and irregular symptoms, like headache, vomiting diarrhea sore throat, confusion, and muscle pain $[35,46]$ are descried in literature. Bilateral pneumonia [35,43] $1 / 4$ and $1 / 3$ of Wuhan hospitalized cases developed serious complications, like shock, arrhythmia, acute respiratory distress syndrome need urgent intensive care unit $[32,43,46]$.

\section{Diagnosis}

Epidemiologic information basically travelling history is one of the important factor in diagnosis here (for example a travel history or residence in the affected area two weeks before the symptoms start), As any disease condition clinical manifestation, Radiographical findings in specific CT imaging, and blood, saliva laboratory sample tests These diagnostic rules are determined based on the standards of Chinese National Health Commission or World health Organization to of either the WHO $[47,48]$.

Salivary diagnosis platforms need to emphasis as some strains of the virus were discovered in saliva even 29 days after the case reported $[49,50]$. Samples of saliva can be gathered in cases who present with oropharyngeal secretions as a symptom [51,52]. Table 1 explains list of questioner used for scheduled patients for endoscope procedure; these questioners prepared to evaluate or screen the COVID virus in these scheduled patients. We think it's liable to be applied for dental patients too as initial screening purposes.

\section{Treatment}

To date, there no evidence was found from random control trials to suggest special anti-CoV treatments; only supportive administration of COVID-19 is established [41]. Presently, the COVID-19 approach is sourcing control of infection; control and prevention transmission risks; isolation and early diagnosis for infected patients [43] these are major roles for outbreak control.

Wei-jie Guan [35] stated that intravenous antibiotics, mechanical ventilation and oxygen therapy; and overall were initiated in $35.8 \%, 6.1 \%$, $57.5 \%$, and $38.0 \%$, of infected cases , correspondingly. These therapies have been taken in noticeably high percentages of hard cases (all $P<0.05$ ).

\section{Dentist Role}

\section{Dental Clinic as Possible Transmission Route of Infection}

Robinson Sabino [23] in his published study consider dental procedures are high risk procedure as airborne inhalation of aerosols and particles practiced during dentist steps on COVID-19 infected cases make dentists exposed closely and directly to the virus. Consequently, it is vital for dentists to take protection techniques to stop the infection of COVID-19. In this article we discuss the preventive policies should be well known for dentist by focusing on placement of patient, hygiene of hands, personal protective equipment (PPE), and caution in performing procedures of aerosol-generating.

Table 1: COVID Screening Questioners cited from Amber Ather [15]

\begin{tabular}{|c|c|c|}
\hline \multirow{3}{*}{$\begin{array}{l}\text { Name: } \\
\text { Date of Birth: } \\
\text { COVID Screening Questioners }\end{array}$} & \multicolumn{2}{|l|}{ Date: } \\
\hline & & \\
\hline & Yes & No \\
\hline \multicolumn{3}{|l|}{ In the past 14 days, have you or any household member travel to area with known cases of COVID V. infection } \\
\hline \multicolumn{3}{|l|}{ In the past 14 days, have you or any household member had contact with known cases of COVID V. infection } \\
\hline \multicolumn{3}{|l|}{ have you or any household member had history of exposure to COVID biologic materials } \\
\hline \multicolumn{3}{|l|}{ In the past 14 days, have you had history of fever } \\
\hline \multicolumn{3}{|l|}{ In the past 14 days, have you had any symptoms as cough, diarrhea, difficulties in breathing, nausea, body ach, extra.... } \\
\hline Urgent Dental Need Question (Do you have Un controlled dental or oral pain, infection, swelling, or bleeding or trauma in your mouth) & & \\
\hline
\end{tabular}


We explain earlier that one of important route of transmission is airborne particles in noso-oral-pharyngeal area. To, K. et al. [53] reported that viral culture method used to detect presence of live viruses in infected persons and virus can live up to 29 days in saliva 43 this related to specific characters of COVID virus which has th ability to utilize ACE2 effectively as a receiver to invade cells, that possibly be similar to type of transmission "human-to-human" [54]. ACE2 abundantly present along the respiratory tract, beside that salivary gland duct cell morphologically also compatible and approved to be a class early targets for 2019-nCoV as well as previously discovered SARSCoV infection [55].

From this point of view dental professionals and their patients couldn't protect themselvesfrom pathogenic microorganisms both bacteria and viruses which manifest within the respiratory tract and oral cavity. In these exceptional circumstances, professionals dentist care hold the infection risk of 2019-nCoV because of the specificity of the profession dealing, including communication type with patient which is "face-to-face" instruments handling, blood, saliva, , exposure.

Through inhalation of microorganisms of airborne that last in the air for long time [56] oral fluids, blood, or direct dealing with patient materials [57]. Coughing and talking with an infected persons and persuade a short distance without a mask can induce transmission of droplets and aerosols containing microorganisms dental settings $[58,59]$.

In addition contaminated instruments and/or environmental surfaces indirect contact [60] These are the specific method of dissemination involved in an infected individual in dental clinics and hospitals especially during the outbreak of 2019-nCoV.

\section{Airborne Spread}

Many literatures discuss the hard acute respiratory syndrome caused by coronavirus airborne spread of SARS-Cov. Dental researches explain that several steps that dentist practice can make droplets and aerosols are polluted with virus [58,60]. Moreover Airborne spread of 2019$\mathrm{nCoV}$ are the biggest distress in hospitals and dental clinics (Figure 2). Beside patients breathing and cough of patients whether infected or not. Dental hand piece and turbines devices with, it's widely use in dental clinics and hospitals rotate with high speed with running water, when its used in patient's oral cavity generating, a big amount of droplets and aerosol mixed with saliv or blood of patients As the size of these aerosols and droplets particle is small, they can stay for long period before settle on environmental surfaces or entering the respiratory tract This, explain spread of the 2019-nCoV in dental clinics and hospitals.

\section{Contact Spread}

Cleveland, J. L. et al. in his article advocate that contact spread also one of transmission ways of virus in dental clinics as commonly dental professional are contact directly or indirectly with patient materials, saliva, blood, , and contaminated environmental surfaces or dental instruments [58].

\section{Contaminated Surfaces Spread}

Articles estimated that contaminated surfaces spread of different species of Coronavirus is able to last on surfaces like plastic metal or glass, for 14 days $[56,61]$. Thus, polluted surfaces which are contacted frequently in healthcare places are a potential.

\section{Patient Management and Prevention of Nosocomial Infection}

Coronavirus outbreak causes extraordinary public health challenge for all individual in various names. Responsibilities of outbreak and protection of people from such disasters infection are rests on each person starting with individuals, society, states, health and nongovernorates institutions even military actors. All precautions and management of the Wuhan crisis are on previous outbreak experience of SARS-CoV-2 and SARS-CoV and its related disease (COVID-19).

We briefly highlight the significant evidence needed to be known by dentist as they have essential role in transmission. Dental professionals should follow specific procedures for management pf their patient's in COVID-19 epidemic period.

One of the most important recommendations is to delay minor procedures for at minimum, three weeks exclusively, dentist provide emergencies American Dental Association recommended in March 16,2020 , list of advices for dental procedures [15].

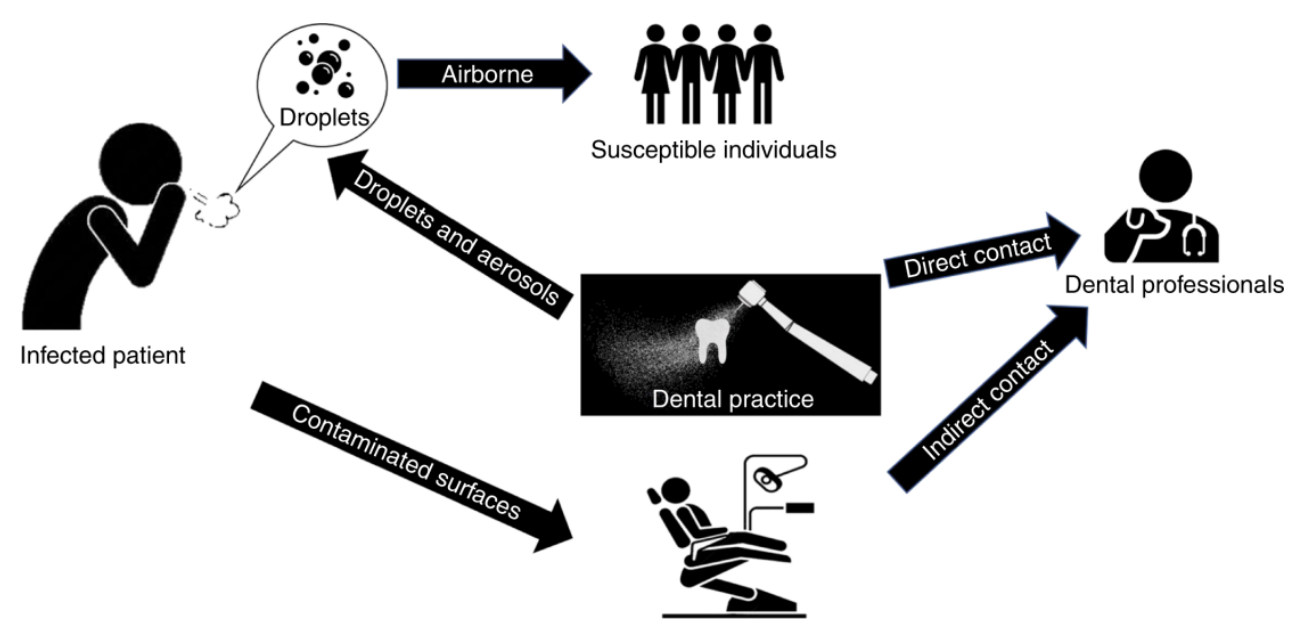

Figure 2: Transmission Routes in Dental Clinics and Hospitals. Cited from Xian Peng [71]. 


\section{Initial Screening}

We explain previously that early diagnosis COVID-19 infection is crucial for both prevent dissemination transmission and early management and isolation of suspected individuals. Focus on travelling to infected area and symptoms of flue presence (any febrile respiratory illness). Tracking of reporting cases can be done through many public sources (Figure 3).

Depending on answer; dental professional can manage. Positive response to questions is able to advance early worry and prefer to defer minor dentist care for 14-21 days minimum (incubation period).

\section{Risk Level Classification and Emergency Evaluation of Dental Patients}

In the dental practice, complete medical history is mandatory with the screening questioner, detection of Potential COVID Virus
Risk level in patients (Table 2) and evaluation of specific emergency correctly too. It's vital to measure the body temperature of the patient using infrared thermal sensors cameras or a remote forehead thermometer [62]. Elective dental care deferred also as in role one if patient temperature is $\left[>100.4^{\circ} \mathrm{F}=38^{\circ} \mathrm{C}\right]$ and/or respiratory disease symptom observed.

Isolation of Patients in the Clinic or Hospitals: Suspected individual should be separated in well-ventilated waiting place 6 feet minimum from the normal patients looking for dental care [63]. Patient are advised to use medical masks and use respiratory hygiene, like covering the nose and mouth by tissue when sneezing and coughing, and then throw the tissue [63].These are the guidelines recommended by the Centers for Disease Control and Prevention (CDC) Moreover we have to educate patient for self -quarantine them and consult their doctors to check the possibility of being infected with COVID-19.

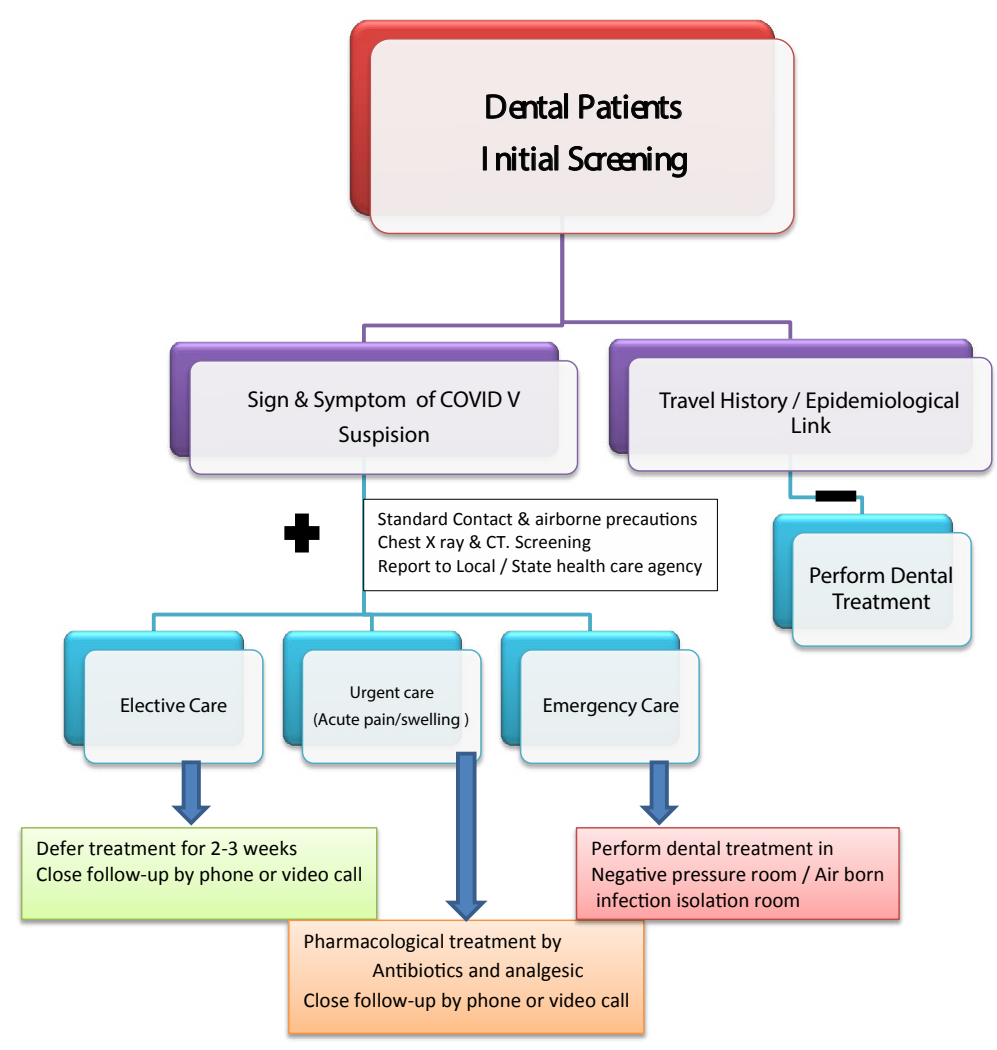

Figure 3: Dental Patient Screening of COVID V and Dental Management cited from Amber Ather [15].

Table 2: Potential COVID Virus Risk Classification Cited from Alessandro Repici [72].

\begin{tabular}{|c|c|c|}
\hline Risk & Clinical Picture & \\
\hline \multirow{3}{*}{ Low } & \multirow{3}{*}{ No } & No Symptom (cough, fever...) \\
\hline & & No contact with positive infected persons \\
\hline & & Non stay in high risk area during last 14 days \\
\hline \multirow{4}{*}{ Intermediate Risk } & \multirow{2}{*}{ Presence of Symptom with } & No Medical History for contact with positive persons \\
\hline & & Non stay in high risk area during last 14 days \\
\hline & \multirow{2}{*}{ No Symptom/but } & Contact with positive infected persons \\
\hline & & Stay in high risk area during last 14 days \\
\hline \multirow{2}{*}{ High Risk* } & \multirow{2}{*}{ At least 1 Symptom +1 of the following } & Contact with positive infected persons \\
\hline & & Stay in high risk area during last 14 days \\
\hline
\end{tabular}

${ }^{\star}$ In an emergency setting, all procedures must be considered high risk if adequate history can't be assessed. 
Pharmacologic Management: In presence of true emergency dental care like tooth pain and or swelling in infected or suspected individuals, its preferable to manage with analgesics or/and antibiotics as alternative which can give good relief in addition it offers dentist time to make a prcedures to give teeth care with suitable measures in clinic to hinder the transmission (Figure 4).

\section{Special Dental Recommendation in Treatment}

Dental treatment decision can depend on case assessment with emergency questioner. Mostly active patients not present to dental units seeking treatment only in case of trauma presence or in sever space infection which might need surgical intervention.

Under these critical situations which is fill of danger that can be faced by dental professional in specialized dental health care centers or hospitals, dentist should be aware and alert for some definite and precise recommendation which are estimated and published in various articles since attack and outbreak of COVID virus. These are:

- Personal protective equipment $[\mathrm{PPE}]$ and hand hygiene practices used appropriately to prevent direct contact, and airborne (Figures 5-7).

- Patient advice to use mouth rinse before intervention. Various published articles estimate that previous studies have shown that SARS and MERS were highly susceptible to povidone mouth rinse [64]. Therefore, pre procedural mouth rinse with $0.2 \%$ povidone-iodine might reduce the load of corona viruses in saliva $[62,65]$.
- Disposable equipment use mandatory such as mouth mirror, syringes and blood pressure cuff to prevent crosscontamination.

- Intraoral imaging should be avoided as it can initiate gag reflex. Instead extraoral imaging such as panoramic radiograph or СВСТ. In special situations when intraoral imaging is required, sensors should be double barrier to prevent perforation and cross-contamination [66].

- Rubber dam use highly indicated as it's minimizing splatter generation and it covers the nose.

- High risk of contaminated droplet spread through use of high speed handpieces, triple syringe and ultrasonic instruments for these reason dentists should reduce the use of high-speed handpieces and three-way syringes.

- Routine dental practice setting is not suitable for suspected or confirmed patients [63]

- Human coronavirus can survive on inanimate surfaces up to 9 days at room temperature, with a greater preference for humid conditions [56]. Therefore, clinic staff should make sure to disinfect inanimate surfaces using chemicals recently approved for COVID-19 and maintain a dry environment to curb the spread of SARS-CoV-2 [67].

- Universal precautions are cleared by the American Dental Association [ADA] all over the worlds which focus on those dentists nationwide deferred any elective treatment up to 2-3

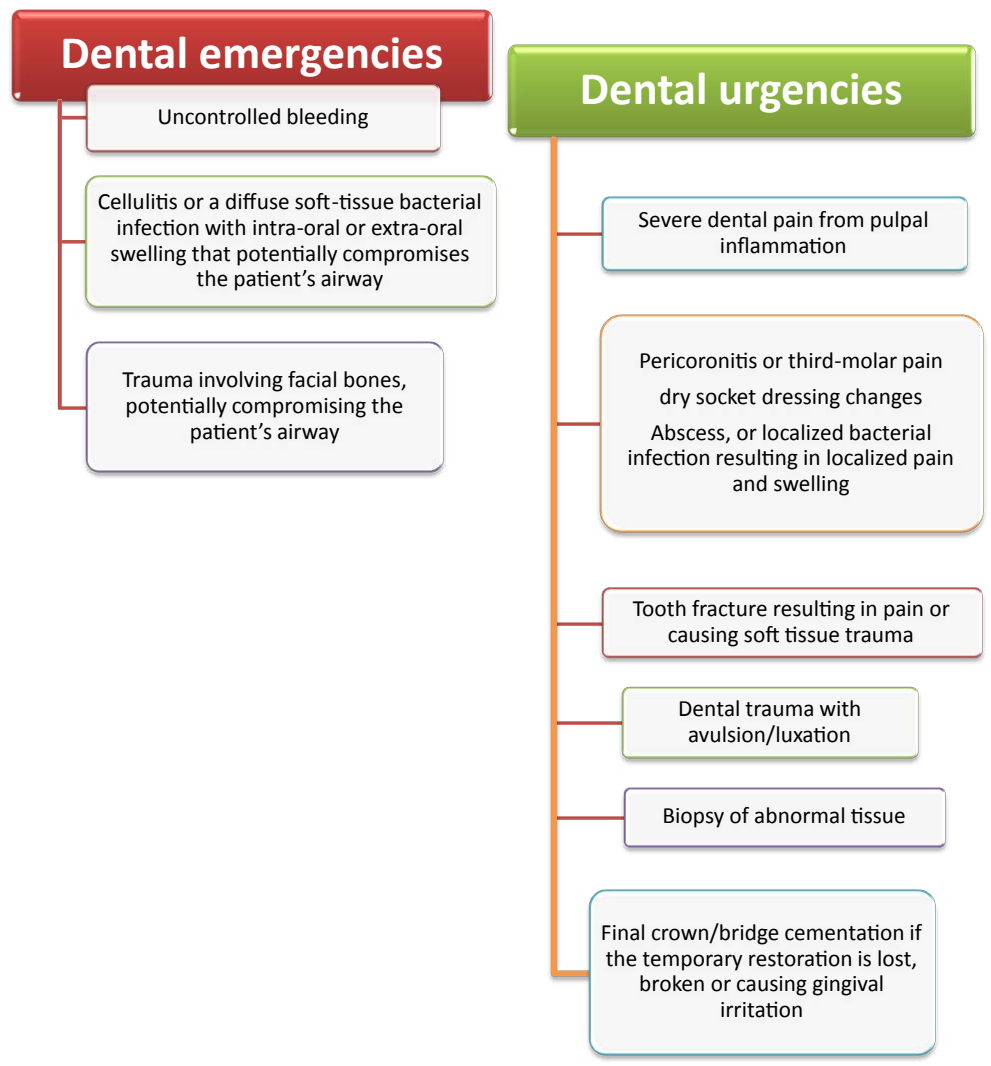

Figure 4: American Dental Association: Interim Guidance for Management of Emergency and Urgent Dental Care. Cited from Ciro Bocchetti [73]. 


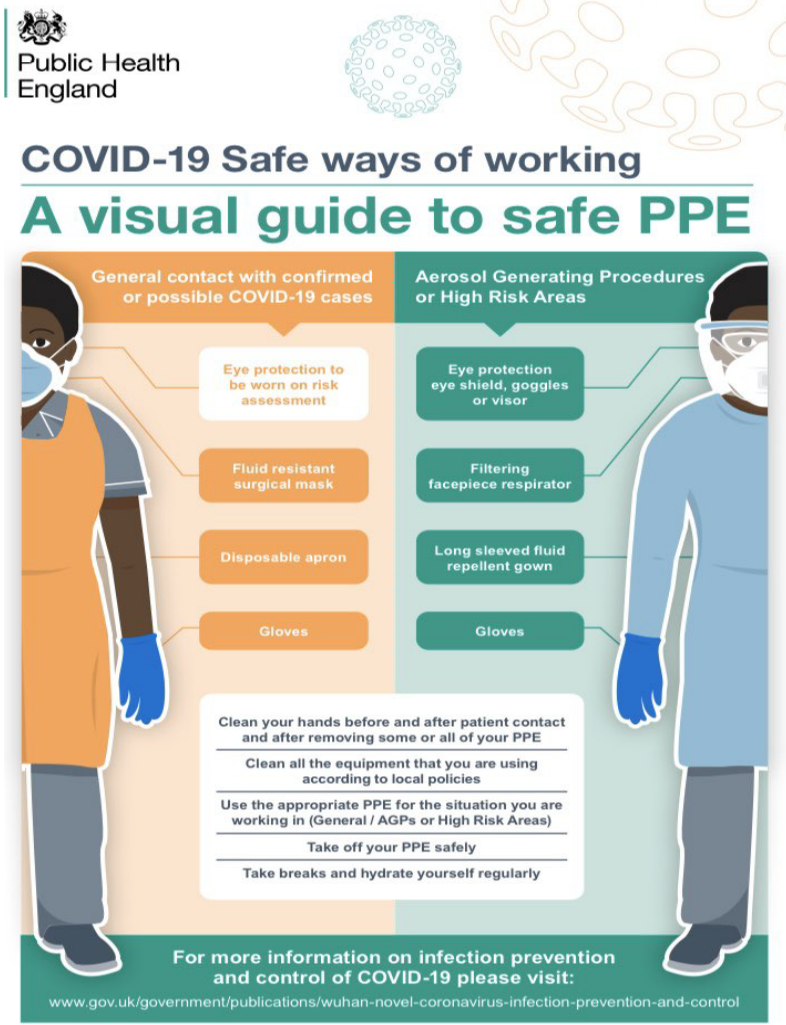

Figure 5: A visual guide to safe PPE Cited from Public Health England Gateway [74].

\begin{tabular}{|ll} 
Quick guide & Quic \\
Public Health & Putting on (donning) personal protective \\
England & $\begin{array}{l}\text { equipment (PPE) for aerosol generating } \\
\text { procedures (AGPs) }\end{array}$
\end{tabular}

This is undertaken outside the patient's room.

\section{Pre-donning instructions}

- ensure healthcare worker hydrated

- tie hair back

- remove jewellery

Perform hand

hygiene before

- check PPE in the correct size is available

\section{1}

Put on the long-sleeved fluid repellent disposable gown

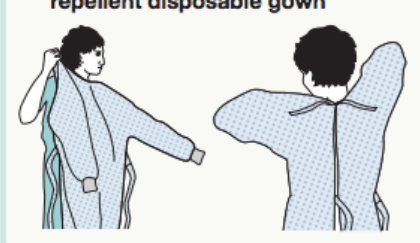

2 putting on PPE

3

Eye protection

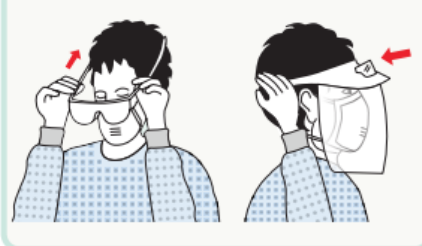

Respirator Perform a fit check.

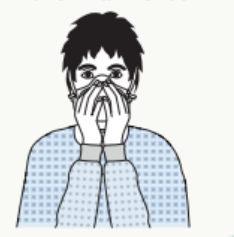

\section{4}

Gloves

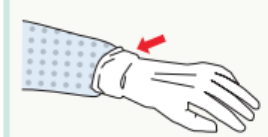

Figure 6: Covid-19 Protection (PPE) - Putting-on-for-Aerosol-Procedure Cited from Guidance Public Health England [75]. 


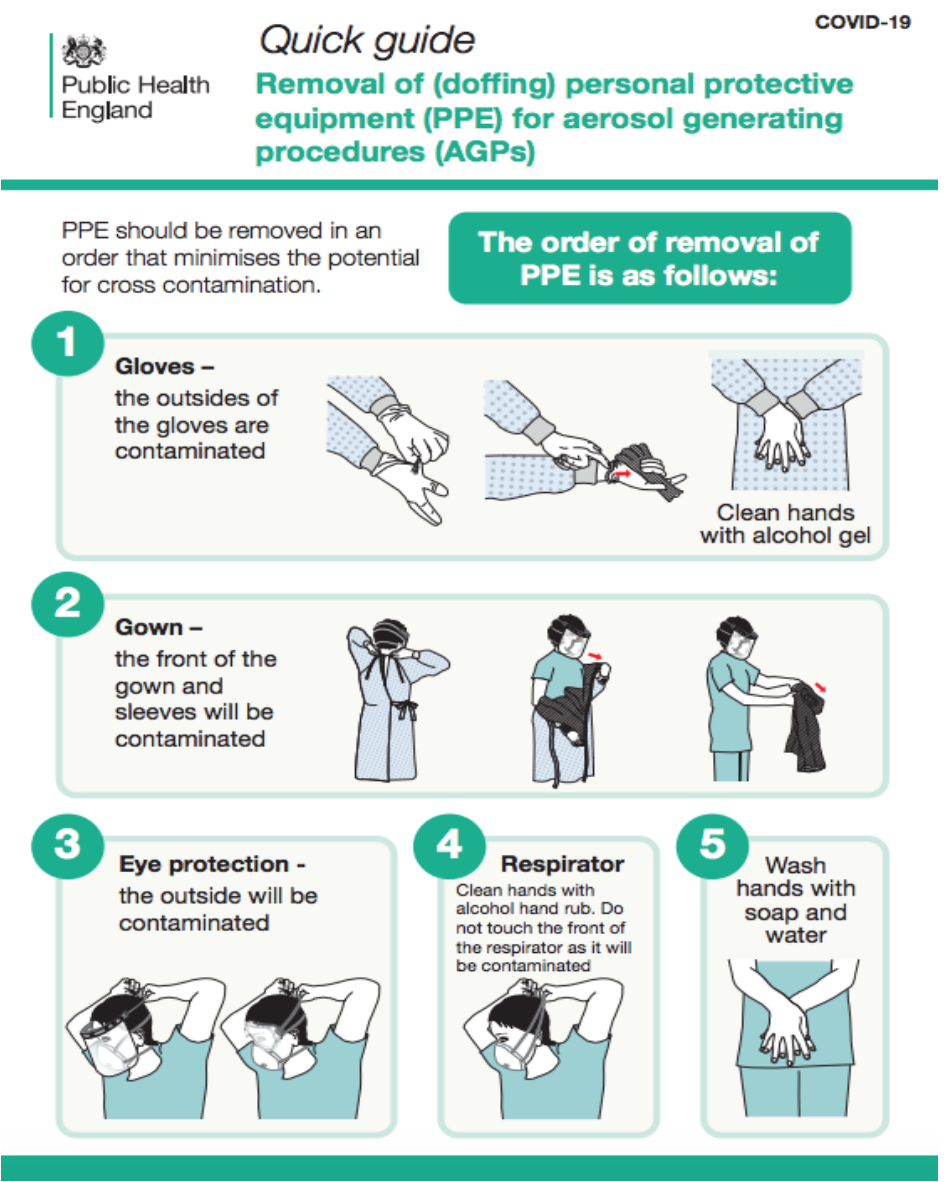

Figure 7: Covid-19 Protection (PPE) - Doffing-for-Aerosol-Procedures Cited from Guidance Public Health England [75].

weeks. Emergency treatments take place with high precaution under the idea that patients supposed to be asymptomatically infected with COVID virus $[68,69]$.

- Dentist as health care providers must keep themselves up to date about this evolving disease and provide adequate training to their staff to promote many levels of screening and preventive measures

\section{State Responsibilities in COVID Outbreak}

Politically, related to the crisis all efforts from the Prime Minister as well as other ministers such as (Ministry of Education, Ministry of Defense) also Civil Society Institutions, Medical and Dental Associations extra, gathered to support ministry of Health and World Health Organization in Iraq. To avoid transmission and dissemination, certain recommendation followed nationally and applied in my country too through the decision of Iraqi Health Minister. These recommendations briefly are:

\section{Anticipation and Control Measures}

- Forming the Epidemiological Crisis Control Committee responsible for Evidence-based control strategy decision making and adjustments is the key epidemic indicator. Responsibilities of committee to declare and aware institutions about effect of infection prevention and control [IPC] measures in various health care settings.
- Responsibilities also to pursuit entry and exit screening for individuals travelling and be aware of its effect public health control measures and their socio-economic impact. Movement restriction, Impose of curfew for emergency only, School and workplace closures all these actions were taken to avoid outbreak. Moreover educate individuals about Social distancing importance wearing mask in general public, mandatory quarantine for proved infected persons and voluntary quarantine with active surveillance.

- Different stages of outbreak should be assessed, risk, capacities and time screening is crucial in program recommendations, assess response of infected individuals all this aims to reach balance between reposes and social development.

- Initiate timely scientific evidence based, efficient and flexible joint multi-sectorial mechanism, which is driven by strong government leadership.

\section{Practical Recommendations which Depend on Published Articles}

- Keep in touch with the newly observed surveillance all over the country with early investigation priorities.

- Sharing information on patient management, disease progression and severity and favorable management outcomes.

- Estimation of Clinical care and infection control according 
to national evidence based guidelines as example isolation of suspected patients in special pre equipped prepared well centers.

- Instruct all health care workers with specific to physicians to be alert for detection of cases can be infected with COVID-19 as well as ensure maintenance of usual and essential services during the outbreak.

- Encourage pathogenesis studies can be accomplished using biopsy/post-mortem specimens of COVID-19 patients.

\section{Nineveh Local Dealing Measures for COVID Virus Outbreak Crisis}

Governorate represented by the Governor' rule, Nineveh Health Directorate with specification for my institution ( Al-Salam Teaching Hospital), Crisis Cell Committee, Army and Police leaderships joined forces and efforts to take all local protection measures to avoid the spread of the disease all over the governorate. Follow guidelines on evidence based policy with continued recommendation and observation of the Ministry of Health and World Health Organization taking into account the outbreak scenarios in other countries whether near or far with all expectations to what happen in the next step.

The most vital recommendations in general speaking are:

- Prevent traveling; close all local borders avoiding entry and exit for any persons.

- Prepare health care providers in different specialties and in all grades, learn them to be aware for the disease as a whole. Deal with persons attained as suspicious till prove otherwise that mean take all precautions of safe distance, mask, gown, avoid direct contact with saliva, blood and other body fluids.

- Educate individuals as much as possible how to avoid transmission, safety contact, observe abnormal clinical symptoms, self - quarantine, urgent seeking contact if suspicion present.

- Stop institutional works, schools and universities.

- Impose a curfew with exception for emergencies and health care workers.

- Prepare special quarantine hospitals for suspected and confirmed cases. Highly equipped isolated rooms arranged to manage the patients in all circumstances. Al-Salam Teaching Hospital and Al-Shifaa General Hospital are chosen to be arranged for receive suspected and confirmed cases.

- Prevent dentist from practice work in their clinics and advice dental health centers to deal with only critical cases under precautions with as possible defer any treatment can establish infection.

\section{Conclusion}

In conclusion, protection of public in an intensive crisis such as Corona virus disaster are responsibilities of all with no exception starting from individuals themselves and ending with the Prime Minister. Great duties are established on healthcare workers and maintaining high standards of care and infection control are priorities for all. Its logical from the evidence based research that dealing with the crisis is challenge to all, moreover is imperative to improve current real strategies for anticipation and protection.

Dentist as eminent segment of the society are liable to handle their role in prevention and protection against outbreak of the crisis. We focus on saliva essential role in the human-to-human transmission and diagnosis of COVID-19 infection positivity of cases. Dental care providers need to be aware and prepared for tackling any impending infectious disease challenge which can be life threatening to susceptible patients.

All what described previously, is a brief review can be used for starting education argument and continue to be updated by others.

\section{Review Limitations}

Need more detailed descriptions in each part of the study with referral to clinical cases studies.

\section{Acknowledgement}

To all persons lift up the legend of public protection as priorities.

All my Institution Members as they pay great efforts to help COVID 19 patients

To all health care workers are; involving dentists.

To the sole of all Health Care Workers attacked by the COVID 19 and lost their lives.

\section{Reference}

1. Weiss SR, Leibowitz JL (2011) Corona virus pathogenesis. Adv Virus Res 81: 85-164.

2. World Health Organization (2020) Coronavirus disease [COVID-2019] situation reportd50. Accessed March 10.

3. World Health Organization (2020) Pneumonia of unknown caused China. Accessed February 14.

4. Lu R, Zhao X, Li J, Juan Li, Peihua Niu, et al. (2020) Genomic characterization and epidemiology of 2019 novel coronavirus: implications of virus origins and receptor binding. Lancet 395: 565-574. [crossref]

5. World Health Organization. 2020. Coronavirus disease 2019 [COVID-19]: situation report-36 [accessed 2020 Feb 26]

6. Chan JF, Yuan S, Kok KH, Wang To KK, Hin Chu, et al. (2020) A familial cluster of pneumonia associated with the 2019 novel coronavirus indicating person-to-person transmission: a study of a family cluster. Lancet.

7. Phan LT, Nguyen TV, Luong QC, Nguyen TV, Nguyen HT, et al. (2020) Importation and human-to-human transmission of a novel coronavirus in Vietnam. N Engl J Med 382: 872-874. [crossref]

8. Rothe C, Schunk M, Sothmann P, Camilla Rothe, Mirjam Schunk, et al. (2020) Transmission of 2019-nCoV infection from an asymptomatic contact in Germany. N Engl J Med 382: 970-971. [crossref]

9. Wu JT, Leung K, Leung GM (2020) Now casting and forecasting the potential domestic and international spread of the 2019-nCoV outbreak originating in Wuhan, China: A modeling study. Lancet 395: 689-697. [crossref]

10. Li Q, Guan X, Wu P, Wang X, Lei Z, et al. (2020) Early transmission dynamics in Wuhan, China, of novel coronavirus-infected pneumonia. N Engl J Med 382: 11991207. [crossref] 
11. WHO main website. https://www.who.int [accessed February 5th, 2020] [crossref]

12. Worldometer Coronavirus Population COVID-19 Coronavirus/Death Rate Updates: Coronavirus [COVID-19] Mortality Rate.

13. Weier Wang, Jianming Tang Fangqiang Wei (2020) Updated understanding of the outbreak of 2019 novel coronavirus [2019nCoV] in Wuhan, China. Journal of Medical Virology 92: 441-447. [crossref]

14. Meng L, Hua F, Bian F (2020) Coronavirus Disease 2019 [COVID-19]: Emerging and Future Challenges for Dental and Oral Medicine. Journal of Dental Research 99: 481-487. [crossref]

15. Amber A, Biraj P, Nikita BR, Anibal D, Kenneth MH (2020) Coronavirus Disease 19 [COVID-19]: Implications for Clinical Dental Care Journal of Endodontics 46.

16. North Carolina Department of Health and Human Services (2020) Interim Coronavirus Disease 2019 [COVID-19] Guidance for Dental Providers.

17. National Center for Immunization and Respiratory Diseases [NCIRD], Division of Viral Diseases: Human Coronavirus Types.

18. Chan JF, Yuan S, Kok KH, To KK, Chu H, et al. (2020) A familial cluster of pneumonia associated with the 2019 novel coronavirus indicating person-to-person transmission: a study of a family cluster. Lancet 395: 514-523.

19. Del Rio C, Malani PN (2020) Novel Coronavirus-Important Information for Clinicians. JAMA. [crossref]

20. Centers for Disease Control and Prevention (2020) Disease burden of influenza; [accessed 2020 Feb 25].

21. Brij K (2017) The composition, function and role of saliva in maintaining oral health: A review Article. International Journal of Contemporary Dental and Medical Reviews.

22. Hamid RF, Seied OK, Dana Z, Kim SG, Behzad C (2020) Being a front-line dentist during the Covid19 pandemic: a literature review. Maxillofacial Plastic and Reconstructive Surgery 42: 12. [crossref]

23. Robinson SS, Ana C, Gomes J, Walter LS (2020) Coronavirus COVID-19 impacts to dentistry and potential salivary diagnosis. Clinical Oral Investigations 24: 1619-1621. [crossref]

24. Istituto SS, Sorveglianza I (2020) COVID-19 in Italia (February 27, 2020).

25. Labour, Welfare, KATO (2020) Coronavirus disease 2019 [COVID-19] situation within and outside the country. Press Conference, Minstry of Health.

26. Hoehl S, Rabenau H, Berger A, Kortenbusch M, Cinatl J, et al. (2020) Evidence of SARS-CoV-2 Infection in Returning Travelers from Wuhan, China. N Engl J Med 382: 1278-1280. [crossref]

27. World Health Organization [WHO] (2020) Report of the WHO-China Joint Mission on Coronavirus Disease 2019 [COVID-19].

28. Ganyani T, Kremer C, Chen D, Torneri A, Faes C, et al. (2020) Estimating the generation interval for COVID-19 based on symptom onset data. medRxiv.

29. Nishiura H, Linton NM, Akhmetzhanov AR (2020) Serial interval of novel coronavirus [COVID-19] infections. International Journal of Infectious Diseases. 93: 284-286. [crossref]

30. Liang W, Guan W, Chen R, Wang W, Li J, et al. (2020) Cancer patients in SARS-CoV-2 infection: a nationwide analysis in China. Lancet Oncology 21: 335-337. [crossref]

31. Chen N, Zhou M, Dong X, Qu J, Gong F, et al. (2020) Epidemiological and clinical characteristics of 99 cases of 2019 novel coronavirus pneumonia in Wuhan, China: a descriptive study. Lancet. 395: 507-13. [crossref]

32. Huang C, Wang Y, Li X, Ren L, Zhao J, et al. (2020) Clinical features of patients infected with 2019 novel coronavirus in Wuhan, China. Lancet 395: 497-506.

33. Fei TY, Ronghui Du, Guohui F, Ying L, Zhibo L, et al. (2020) Clinical course and risk factors for mortality of adult inpatients with COVID-19 in Wuhan, China: a retrospective cohort study. Lancet 395: 1054-1062. [crossref]

34. World Health Organization (WHO). Report of the WHO-China Joint Mission on Coronavirus Disease 2019 (COVID-19) 2020.
35. Wei-jie G, Zheng-yi Ni , Yu Hu, Wen-hua L, Chun-quan O, et al. (2020) Clinical characteristics of 2019 novel coronavirus infection in China. Original article. New England Journal of Medicine 382: 18

36. Cai G (2020) Bulk and single-cell transcriptomics identify tobacco-use disparity in lung gene expression of ACE2, the receptor of 2019-nCov. medRxiv.

37. Duclos GE, Teixeira VH, Autissier P, Yaron BG , Marjan AR, et al. (2019) Characterizing smoking-induced transcriptional heterogeneity in the human bronchial epithelium at single-cell resolution. Sci Adv 5: 3413. [crossref]

38. Chen YS, Qian K (2020) Asians Do Not Exhibit Elevated Expression or Unique Genetic Polymorphisms for ACE2, the Cell-Entry Receptor of SARS-CoV-2. Preprints.

39. Mengyuan LL, Yue Z, Wang X (2020) An Investigation of the Expression of 2019 Novel Coronavirus Cell Receptor Gene ACE2 in a Wide Variety of Human Tissues [Preprint]. Research Square.

40. Bi Q, Wu Y, Mei S, Ye C, Zou X, et al. (2020) Epidemiology and Transmission of COVID-19 in Shenzhen China: Analysis of 391 cases and 1,286 of their close contacts. medRxiv.

41. World Health Organization - China Report of the WHO-China Joint Mission on Coronavirus Disease [COVID-19]. 16-24 February 2020.

42. Kui L, Fang YY, Deng Y, Liu W, Wang MF, et al. (2020) Clinical characteristics of novel coronavirus cases in tertiary hospitals in Hubei province. Chin Med J [Engl]. [crossref]

43. Wang D, Hu B, Hu C, Zhu F, Liu X, et al. (2020) Clinical characteristics of 138 hospitalized patients with 2019 novel coronavirus-infected pneumonia in Wuhan, China. JAMA.

44. Yang Y, Lu Q, Liu M, Wang Y, Zhang A, et al. (2020) Epidemiological and clinical features of the 2019 novel coronavirus outbreak in China. medRxiv.

45. Backer JA, Klinkenberg D, Wallinga J (2020) Incubation period of 2019 novel coronavirus [2019-nCoV] infections among travellers from Wuhan, China, 20-28 January. Euro Surveill 25: 2000062. [crossref]

46. Zhu H, Wang L, Fang C, Peng S, Zhang L, et al. (2020) Clinical analysis of 10 neonates born to mothers with 2019-nCoV pneumonia. Transl Pediatr.2020. 9: 5160. [crossref]

47. World Health Organization (2020) Clinical management of severe acute respiratory infection when novel coronavirus [2019-nCoV] infection is suspected: interim guidance [accessed 2020 Feb 17].

48. National Health Commission of China. (2020) An update of novel coronavirus pneumonia outbreak as of 24:00 on February 25 [accessed 2020 Feb 26].

49. Barzon L, Pacenti M, Berto A, Sinigaglia A, Franchin E, et al. (2016) Isolation of infectious Zika virus from saliva and prolonged viral RNA shedding in a traveller returning from the Dominican Republic to Italy, January 2016. Euro Surveill 21: 30159. [crossref]

50. Zuanazzi D, Arts EJ, Jorge PK, Mulyar Y, Gibson R, et al. (2017) Postnatal identification of zika virus peptides from saliva. J Dent Res 96: 1078-1084. [crossref]

51. Gorbalenya AE, Baker SC, Baric RS, Groot RJ, Drosten C, et al. (2020) Severe acute respiratory syndrome-related coronavirus: The species and its viruses-a statement of the Coronavirus Study Group.

52. Fehr AR, Perlman S (2015) Coronaviruses: an overview of their replication and pathogenesis. Methods Mol. Biol. 1282: 1-23.

53. Tsang TY, Yip CY, Chan KH, Wu TC, Chan MC, et al. (2020) Consistent detection of 2019 novel coronavirus in saliva. Clin Infect Diseases. [crossref]

54. Zhou P, Yang XL, Wang XG, Shi ZL, Hu B, et al. (2020) A pneumonia outbreak associated with a new coronavirus of probable bat origin. Nature 579: 270-273. [crossref]

55. Liu L, Wei Q, Alvarez X, Wang H, Zhu Z, et al. (2011) Epithelial cells lining salivary gland ducts are early target cells of severe acute respiratory syndrome coronavirus infection in the upper respiratory tracts of rhesus macaques. J Virol 85: 4025-4030. [crossref]

56. Kampf G, Todt D, Pfaender S, Steinmann E (2020) Persistence of coronaviruses on inanimate surfaces and its inactivation with biocidal agents. J Hosp Infect 104: 246251. [crossref] 
57. Chen, J (2020) Pathogenicity and transmissibility of 2019-nCoV-a quick overview and comparison with other emerging viruses. Microb Infect. Volume 22: 69-71.

58. Cleveland JL, Gray SK, Harte JA, Robison VA, Moorman AC, et al. (2016) Transmission of blood-borne pathogens in US dental health care settings: 2016 update. J Am Dent Assoc 147: 729-738. [crossref]

59. Harrel SK, Molinari J (2004) Aerosols and splatter in dentistry: a brief review of the literature and infection control implications. J Amnn Dent Assoc 135:429-437. [crossref]

60. Wei J, Li Y (2016) Airborne spread of infectious agents in the indoor environment. Am J Infect Control 44: 102-108. [crossref]

61. Otter JA, Donskey C, Yezli S, Douthwaite S, Goldenberg SD, et al. (2016) Transmission of SARS and MERS coronaviruses and influenza virus in healthcare settings: the possible role of dry surface contamination. J Hosp Infect. 92: 235-50. [crossref]

62. Hoffmann M, Kleine-Weber H, Schroeder S, Krüger N, Herrler T, et al. (2020) SARSCoV-2 cell entry depends on ACE2 and TMPRSS2 and is blocked by a clinically proven protease inhibitor. Cell 181: 271-280. [crossref]

63. Wang Y, Wang Y, Chen Y, Qin Q (2020) Unique epidemiological and clinical features of the emerging 2019 novel coronavirus pneumonia (COVID-19) implicate special control measures. J Med Virol. 92: 568-576. [crossref]

64. Centers for Disease Control and Prevention (2020) Infection control: severe acute respiratory syndrome coronavirus 2 [SARS-CoV-2].

65. Eggers M, Koburger JT, Eickmann M, Zorn J (2018) In vitro bactericidal and virucidal efficacy of povidone-iodine gargle/mouthwash against respiratory and oral tract pathogens. Infect Dis Ther 7: 249-259. [crossref]
66. Kariwa H, Fujii N, Takashima I (2004) Inactivation of SARS coronavirus by means of povidone-iodine, physical conditions, and chemical reagents. Jpn J Vet Res 52: 105-112.

67. Hokett SD, Honey JR, Ruiz F, Baisden MK, Hoen MM, et al. (2000) Assessing the effectiveness of direct digital radiography barrier sheaths and finger cots. J Am Dent Assoc 131: 463-467. [crossref]

68. Lan L, Xu D, Ye G, Chen X, Shaokang W, et al. (2020) Positive RT-PCR test results in patients recovered from COVID19. JAMA 323: 1502-1503. [crossref]

69. Susan HD, Anty L, Christine (2020) Coronavirus Transmission in the Dental Setting. Decision in Dentistry Journal 6: 27-33.

70. Charles Shepherd ME (2020) Association Guidance Coronavirus (covid-19).

71. Peng X, Xu X, Li Y, Cheng L, Zhou X, et al. (2020) Transmission routes of 2019-nCoV and controls in dental practice. Int J Oral Sci 12: 9.

72. Alessandro Repici, Roberta Maselli, Matteo Colombo, Roberto Gabbiadini, Marco Spadaccini, et al. (2020) Coronavirus (COVID-19) outbreak: what the department of endoscopy should know. GASTROINTESTINAL ENDOSCOPY 92: 192-197. [crossref]

73. Ciro Bocchetti Roberto Sorrentino Fabio Cozzolino. (2020) COVID-19: Dentistry and the new Coronavirus, a compilation from PubMed resources. Pathology and Diagnostic.

74. C Crown copyright 2020. Public Health England Gateway. Number 2019296. Version 1 April 22020

75. Guidance Public Health England COVID-19 personal protective equipment (PPE) Updated 12 April 2020.

\section{Citation:}

Rawaa Younus Al-Rawee, Mustafa Mohammed Saeed (2020) Corona Virus Transmission and Controls Challenge Mystery for Dentists (Systematic Review). J Dent Maxillofacial Res Volume 3(2): 1-11. 